\title{
Paclitaxel, Carboplatin and 1,25-D3 Inhibit Proliferation of Ovarian Cancer Cells In Vitro
}

\author{
TEA KUITTINEN $^{1}$, PÄIVI ROVIO ${ }^{1}$, TIINA LUUKKAALA ${ }^{2,3}$, MARITA LAURILA ${ }^{4}$, \\ SEIJA GRÉNMAN ${ }^{5,6}$, ANNE KALLIONIEMI $^{7,8}$ and JOHANNA MÄENPÄ̈̈ ${ }^{7}$ \\ ${ }^{1}$ Department of Obstetrics and Gynecology, Tampere University Hospital, Tampere, Finland; \\ ${ }^{2}$ Research, Innovation and Development Centre, Tampere University Hospital, Tampere, Finland; \\ ${ }^{3}$ Health Sciences, Faculty of Social Sciences, Tampere University, Tampere, Finland; \\ ${ }^{4}$ Department of Pathology, Fimlab Ltd, Tampere University Hospital, Tampere, Finland; \\ ${ }^{5}$ Department of Obstetrics and Gynecology, Turku University Hospital, Turku, Finland; \\ ${ }^{6}$ University of Turku, Turku, Finland; \\ ${ }^{7}$ TAYS Cancer Centre and Faculty of Medicine and Health Technology, Tampere University, Tampere, Finland; \\ ${ }^{8}$ Fimlab Ltd, Tampere University Hospital, Tampere, Finland
}

\begin{abstract}
Background/Aim: The combination of paclitaxel and carboplatin is the standard chemotherapy for ovarian cancer. Previous studies have implied that vitamin D (1,25-D3) may have growth inhibitory effects in ovarian cancer. This study aimed to investigate the effect of paclitaxel, carboplatin and 1,25-D3 on the growth of ovarian cancer cells in vitro, based on the hypothesis that 1,25-D3 might potentiate the effect of paclitaxel and/or carboplatin. Materials and Methods: Three non-commercial ovarian carcinoma cell lines UT-OVI(mucinous), UT-OV-3B (serous) and UT-OV-4 (endometrioid) were exposed to different concentrations of 1,25-D3, paclitaxel and carboplatin, respectively. The cell viability was measured using a Crystal violet assay kit. The cellular vitamin $D$ receptor (VDR) mRNA levels were measured by qRT-PCR using the LightCycler equipment. Results: The growth-inhibitory effect of the combination of paclitaxel and carboplatin was $56 \%$ in UT$O V-1,33 \%$ in UT-OV-3B and $47 \%$ in UT-OV-4 cells. Single 1,25-D3 $(10 \mu M)$ inhibited the growth of UT-OV-3B and UT-OV4 by $23 \%$ and $28 \%$, respectively, whereas no effect was seen in UT-OV-1 cells. These results are in line with the finding that the expression of VDR was high in UT-OV-3B and UT-OV-4, but very low in UT-OV-1. The combination of 1,25-D3, paclitaxel
\end{abstract}

This article is freely accessible online.

Correspondence to: Tea Kuittinen, Department of Obstetrics and Gynaecology, Tampere University Hospital, Teiskontie 35, 33520 Tampere, Finland. Tel: +358 5031169810, e-mail: tea.kuittinen@fimnet.fi

Key Words: Vitamin D, 1,25-D3, ovarian cancer, in vitro, paclitaxel, carboplatin, growth inhibition, VDR. and carboplatin resulted in $61 \%, 46 \%$ and $58 \%$ growth reduction in UT-OV-1, UT-OV-3B and UT-OV-4 cells, respectively. The additive effect of 1,25-D3 was $21 \%$ in UT-OV4, 20\% in UT-OV-3B and $12 \%$ in UT-OV-1 cell line. Conclusion: The results imply that combining 1,25-D3 with paclitaxel and carboplatin may potentiate their growth inhibitory effect on ovarian cancer cells with high VDR expression.

In 2018 there were approximately 300,000 new ovarian cancer cases worldwide. The estimated incidence was 6.6 and mortality 3.9 per 100,000 women per year. (1). Ovarian cancer is the most lethal malignancy of the female reproductive system. Surgery combined with cytotoxic therapy leads to favorable clinical response in up to $80 \%$ of patients but the majority of patient relapse (2). The overall survival (OS) has marginally increased in the past decades despite advances in chemotherapeutic agents, targeted therapy, and more radical surgery (3). However, complete resection of all visible disease has been shown to significantly improve outcome and OS (4-6).

Calcitriol (1,25-dihydroxycholecalciferol, 1,25-D3) is the hormonally active form of vitamin D. It is well known as an important regulator of calcium synthesis and bone metabolism (7-9). 1,25-D3 attaches to the vitamin D receptor (VDR) in the cell nucleus and this complex interacts with retinoid $X$ receptor ( $R X R$ ) resulting in the regulation of the activity of vitamin D-responsive genes. By turning these genes on or off, the complex helps to control calcium and phosphate absorption and growth regulatory processes in the cell (10-11). 1,25-D3 induces $\mathrm{G}_{0}-\mathrm{G}_{1}$ cell-cycle arrest and thereby stops cell proliferation, triggers VDR-mediated cell death, inhibits angiogenesis, and promotes differentiation in many cancer cells in vitro and in vivo (12-17). The presence 
of functional VDR receptor in tumors and cancer cell lines might thus represent a target for cancer therapy. Disabled VDR activity leads to 1,25-D3 insensitivity, loss of antiproliferative effects, increase in oxidative DNA damage and accelerated tumorigenesis (10-11).

Many different cell types, including normal and malignant ovarian cells, contain VDR and express vitamin D metabolizing enzymes $1 \alpha$-hydroxylase and 24 -hydroxylase to synthesize and degrade active 1,25-D3 locally (18-22). VDRpolymorphisms have been indicated to correlate with a higher risk of ovarian cancer (23). This links vitamin D status with cellular anti-tumor actions, and vitamin D status may be a modulator of cancer progression in persons living with cancer (24-25). In 2016 a large Mendelian randomization study suggested that genetically low major circulating form of vitamin D $(25(\mathrm{OH}) \mathrm{D})$ plasma levels are associated with a higher incidence of ovarian cancer (26). Moreover, higher concentrations of $25(\mathrm{OH}) \mathrm{D}$ seemed to be associated with longer survival rates at the case-control study of 1,600 women diagnosed with epithelial ovarian cancer (27). Also, a metaanalysis of individual cohort studies found a tendency between low circulating $25(\mathrm{OH}) \mathrm{D}$ and ovarian cancer incidence although this finding was not statistically significant (28).

In a previous in vitro study, we demonstrated that 1,25 -D3 combined with paclitaxel and carboplatin, inhibits endometrial cancer cell growth and may even enhance the cytotoxic effect of these agents (29). Ovarian cancer is clinically well known to be sensitive to the combination of paclitaxel and carboplatin (3), which has also been demonstrated in vitro (30-32). Previous in vitro studies have also implied that $1,25-\mathrm{D} 3$ has a growth inhibitory effect on ovarian cancer cells $(22,33,34)$. To our knowledge, however, there are no preclinical studies examining the effect of simultaneous use of paclitaxel, carboplatin and 1,25 -D3 in ovarian cancer cells. The aim of the present study was to test the growth inhibitory effect of these both as single agents and in combination on ovarian cancer cell lines in vitro.

\section{Materials and Methods}

Cell lines. Five non-commercial ovarian cancer cell lines (UT-OV1, UT-OV-2, UT-OV-3A, UT-OV-3B and UT-OV-4) were used in this study. The cell lines were established at the University of Turku, Turku, Finland (35). The cell lines were originally derived from primary or metastatic stage III-IV epithelial ovarian carcinomas. UT-OV-1 was mucinous, UT-OV-2 and UT-OV-4 were endometrioid and UT-OV-3A and -3B were serous cystadenocarcinomas (35).

Cell cultures and treatments. The cells were cultured as described previously (31). The cells were sub-cultured weekly and maintained in a logarithmic phase in $75 \mathrm{~cm}^{2}$ culture flasks in Dulbecco's modified Eagle minimal essential medium (DMEM), containing $10 \%$ fetal bovine serum (FBS), $1 \%$ penicillin/streptomycin, $1 \%$ glutamine and $1 \%$ non-essential amino acids at $37^{\circ} \mathrm{C}$ in a humidified atmosphere supplemented with $5 \% \mathrm{CO}_{2}$. All cell lines were tested for mycoplasma contamination.
Paclitaxel (Hospira $\left.{ }^{\circledR} 6 \mathrm{mg} / \mathrm{ml}, \mathrm{UK}\right)$ and carboplatin $\left(\right.$ Accord $^{\circledR} 10$ $\mathrm{mg} / \mathrm{ml}, \mathrm{UK}$ ) were purchased from the Pharmacy of the Tampere University Hospital. 1,25-D3 was purchased from Sigma-Aldrich (St. Louis, MO, USA). Paclitaxel was initially diluted in $0.9 \%$ sodium chloride to give a $0.1 \mathrm{mM}$ concentration. For each experiment final dilutions of 1-10 nM paclitaxel were prepared in DMEM. Carboplatin was diluted in sterile water to get a stock solution of $100 \mu \mathrm{g} / \mathrm{ml}$ and the final concentrations used were 0.1 $50 \mu \mathrm{g} / \mathrm{ml}$. 1,25-D3 was dissolved in 95\% ethanol and diluted in DMEM to get final concentrations between $10 \mathrm{nM}$ and $10 \mu \mathrm{M}$. All final dilutions were prepared immediately before use. The concentrations of drugs were based on previous reports as well as pharmacological relevance $(29,30,32,36)$.

VDR expression. The VDR mRNA levels in UT-OV-1, UT-OV-2, UT-OV-3A, UT-OV-3B and UT-OV-4 cells were measured by quantitative reverse transcription polymerase chain reaction (qRTPCR) using the LightCycler equipment (Roche, Mannheim, Germany). Total RNA was extracted using the RNeasy Mini Kit (Qiagen, Valencia, CA, USA) and was reverse transcribed with SuperScript ${ }^{\mathrm{TM}}$ First-Strand Synthesis System for RT-PCR (Invitrogen, Carlsbad, CA, USA), as described elsewhere (29). qRTPCR was performed using $20 \mu \mathrm{M}$ gene specific primers (SigmaAldrich, sense 5' ATCGGCATGATGAAGGAGTT 3', antisense 5' TGCTCCTCAGACAGCTTGG 3') and $10 \mu \mathrm{M}$ UPL probe (probe number \#12). The PCR program included the following steps: 10 min denaturation at $95^{\circ} \mathrm{C}$ followed by 45 cycles of $10 \mathrm{~s}$ denaturation at $95^{\circ} \mathrm{C}, 30 \mathrm{~s}$ annealing at $60^{\circ} \mathrm{C}$ and $1 \mathrm{~s}$ elongation at $72^{\circ} \mathrm{C}$. The expression levels were normalized using glyceraldehyde-3phosphate dehydrogenase (GAPD) housekeeping gene.

Cell growth assays. The cells were plated on 96-well plates at 40,000 cells/well (UT-OV-1), at 70,000 cells/well (UT-OV-3B) and at 60,000 cells/well (UT-OV-4) for each experiment, respectively. The number of cells plated per well was adjusted according to the plating efficiency of each cell line. Cells were allowed to adhere overnight and then exposed to indicated concentrations of paclitaxel, carboplatin, and 1,25-D3 alone or in combination for three days. The cell viability was measured using the Crystal violet assay kit (Abcam, Germany). The O.D. of the crystal violet staining was measured at $590 \mathrm{~nm}$ and is directly proportional to the cell biomass. All measurements were performed in six replicates and the individual experiments were repeated three times.

Statistical analyses were carried out using the IBM SPSS Statistics for Windows, Version 22.0. Armonk, IBM Corp. Released 2013, NY: IBM Corp. Independent sample $t$-test were used to compare differences between treatments to investigate the effect of paclitaxel, carboplatin and 1.25-D3.

\section{Results}

Before evaluating the effect of the chemotherapeutic drugs and 1,25-D3, five ovarian carcinoma cell lines were tested for the expression of VDR. VDR-expression was highest in the UTOV-3B and UT-OV-4 cell lines (Figure 1). UT-OV-1 also expressed VDR to some extent. The expression of VDR in the UT-OV-2 and UT-OV-3A cell lines was very low (Figure 1). Hence, the subsequent experiments were performed using only three cell lines: UT-OV-1, OT-OV-3B and UT-OV-4. 


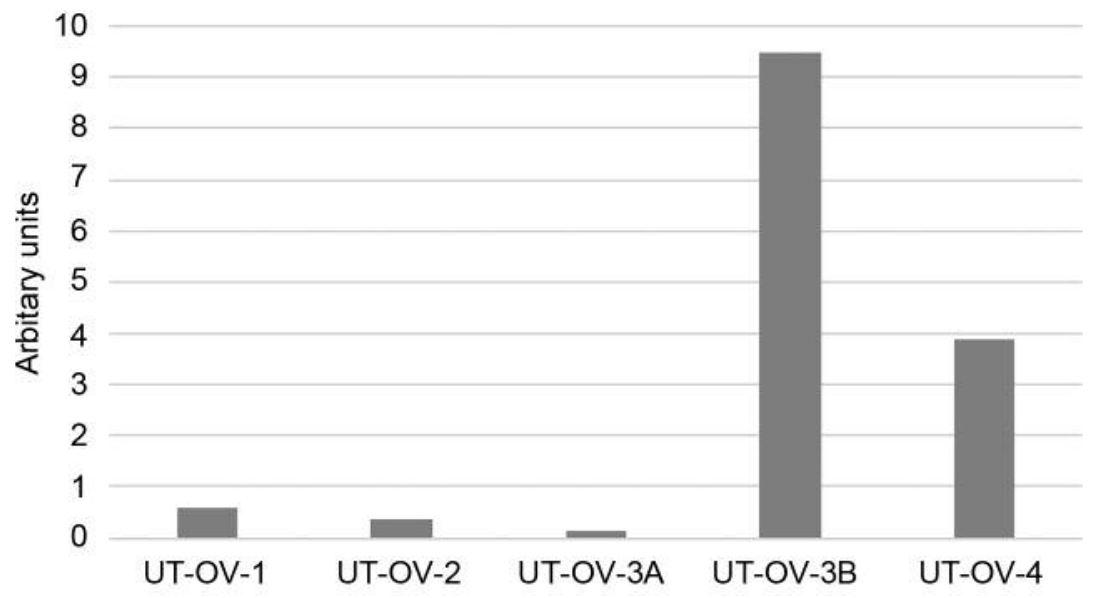

Figure 1. Vitamin D receptor (VDR) expression in UT-OV-1, UT-OV-2, UT-OV-3A, UT-OV-3B and UT-OV-4 ovarian cancer cell lines.

The ovarian carcinoma cell lines were first exposed to different concentrations of 1,25-D3 (10 nM, $50 \mathrm{nM}, 100 \mathrm{nM}$, $1 \mu \mathrm{M}$ and $10 \mu \mathrm{M})$ to determine the estimated drug concentration which causes $25 \%$ growth inhibition $\left(\mathrm{IC}_{25}\right)$ in cancer cell lines expressing VDR. All three cell lines responded poorly to the concentrations of 10 to $100 \mathrm{nM}$ of 1,25-D3. In UT-OV-1 cells, the growth inhibition was even negligible with the higher doses of 1,25-D3: $3 \%$ with $1 \mu \mathrm{M}$ and $4 \%$ with $10 \mu \mathrm{M}$ of $1,25-\mathrm{D} 3$, respectively, when compared to untreated controls. (Figure 2). In UT-OV-3B cells, the corresponding growth inhibitory percentages were $13 \%$ and $26 \%$, and in UT-OV-4 cells $12 \%$ and $32 \%$, respectively (Figure 2). Based on these results, the dose of $10 \mu \mathrm{M}$ of $1,25-\mathrm{D} 3$ was chosen for the next experiments where the effects of the combinations of the cytotoxic agents and 1,25-D3 were evaluated.

Similarly, the cells were cultured with different concentrations of paclitaxel $(1 \mathrm{nM}, 5 \mathrm{nM}$ and $10 \mathrm{nM})$ and carboplatin $(5 \mu \mathrm{g} / \mathrm{ml}, 10 \mu \mathrm{g} / \mathrm{ml}$ and $50 \mu \mathrm{g} / \mathrm{ml})$ to get the estimated drug concentration causing approximately $25 \%$ inhibition of cell growth $\left(\mathrm{IC}_{25}\right)$. In UT-OV-1 cell line, the $\mathrm{IC}_{25}$ concentration of carboplatin was $10 \mu \mathrm{g} / \mathrm{ml}$ and for paclitaxel $5 \mathrm{nM}$ (Figure 3). In UT-OV-3B and UT-OV-4, the corresponding $\mathrm{IC}_{25}$ values for carboplatin were $50 \mu \mathrm{g} / \mathrm{ml}$ and $10 \mu \mathrm{g} / \mathrm{ml}$ and for paclitaxel $5 \mathrm{nM}$ and $1 \mathrm{nM}$, respectively (Figure 3).

Subsequently, each cell line was treated with the chosen concentrations of paclitaxel, carboplatin and 1,25-D3 as single agents as well as with the different combinations of the drugs to assess if there are any synergistic or additive effects between the drugs (Table I, Figure 4).

The growth inhibition in UT-OV-1 cell line was $48 \%$ with paclitaxel alone $(5 \mathrm{nM}), 29 \%$ with carboplatin alone $(10$ $\mu \mathrm{g} / \mathrm{ml}$ ) and $56 \%$ with the combination of the two. The cytotoxic effect of the combination of the two drugs was more effective than single paclitaxel or single carboplatin (both $p<0.001$ ). Single $10 \mu \mathrm{M} 1,25$-D3 inhibited the cell growth by $3 \%$. The growth inhibitory effect of the combinations of paclitaxel and 1,25-D3 and of carboplatin and $1,25-\mathrm{D} 3$ were $50 \%$ and $36 \%(p=0.172$ and $p=0.028)$, respectively. Thus, the combination of the single agents and 1,25-D3 brought a minor significant effect with carboplatin and 1,25-D3. The most effective was the combination of these three drugs with $61 \%$ growth inhibition which achieved statistical significance when compared to the control, to the combination of paclitaxel and carboplatin and to the single paclitaxel $(p<0.001)$. An additive effect of 1,25-D3 with the combination of paclitaxel and carboplatin was demonstrated.

In the UT-OV-3B cell line, the cytotoxic effect of single 5 $\mathrm{nM}$ paclitaxel was $44 \%$ and that of single $50 \mu \mathrm{g} / \mathrm{ml}$ carboplatin $29 \%$. The cytotoxicity of the combination of the two drugs was $33 \%$. Surprisingly, single paclitaxel was thus more effective than the combination with carboplatin $44 \% \mathrm{vs}$. $33 \%(p<0.001)$. Single $10 \mu \mathrm{M} 1,25-\mathrm{D} 3$ inhibited the cell growth by $23 \%$. Single paclitaxel was more efficient than the combination of paclitaxel and 1,25-D3, 44\% vs. 39\%. Thus, no additive or synergistic effect was achieved over single paclitaxel. The growth inhibition seen with the combination of carboplatin and 1,25-D3 was 35\% (compared to single $1,25 \mathrm{D}-3 p<0.001)$. The additive effect with this drug combination was shown and was statistically significant. The cytotoxic effect of the combination of the three drugs (paclitaxel, carboplatin and 1,25-D3) was 46\%. Only a minor additive effect was achieved with this combination over single paclitaxel $(44 \%)$ and it was statistically significant $(p=0.021)$.

In the UT-OV-4 cell line, single $1 \mathrm{nM}$ paclitaxel was more efficient than single $10 \mu \mathrm{g} / \mathrm{ml}$ carboplatin but the combination of two drugs was the most efficient. The growth 
inhibition was $36 \%$ with paclitaxel and $47 \%$ with the combination of paclitaxel and carboplatin $(p<0.001)$. The corresponding percentage for single carboplatin was $30 \%$ and the difference compared to the combination of these two was significant $(p<0.001)$. Single 1,25-D3 $(10 \mu \mathrm{M})$ inhibited the cell growth by $28 \%$. A dose of $10 \mu \mathrm{M}$ of $1,25-\mathrm{D} 3$ combined with carboplatin $10 \mu \mathrm{g} / \mathrm{ml}$ or with $1 \mathrm{nM}$ paclitaxel was equal with the combination of carboplatin and paclitaxel (cytotoxicity of $47 \%, 46 \%$ and $47 \%$ ) (all $p<0.001$ when compared to the control). The suppression of the cell growth in comparison to the control was $58 \%$ with the combination of the three drugs: paclitaxel, carboplatin and 1,25-D3. The additive effect of $1,25-\mathrm{D} 3$ was $21 \%$ when comparing the combination of three drugs to the combination of two drugs: paclitaxel and carboplatin. This difference was statistically significant $(p=0.001)$.

\section{Discussion}

Our preliminary results showed that 1,25-D3 inhibits ovarian cancer cell growth in vitro as a single agent, but also in combination with paclitaxel and carboplatin. The most efficient combination was 1,25-D3, paclitaxel and carboplatin together in all three cell lines. The anti-tumor effect was $61 \%$ in UT-OV-1, $46 \%$ in UT-OV-3B and $58 \%$ in UT-OV-4 cell line. The corresponding numbers for the combination of paclitaxel and carboplatin were 56\%, 33\% and $47 \%$, respectively.

The additive effect of 1,25 -D 3 was $21 \%$ in UT-OV-4, $20 \%$ in UT-OV-3B and $12 \%$ in UT-OV-1 cell line. Furthermore, the combination of carboplatin or paclitaxel with 1,25 -D3 was equal with the combination of paclitaxel and carboplatin in UT-OV-3B and UT-OV-4 cell lines. In the UT-OV-1 cell line the combination of paclitaxel and carboplatin was the most efficient when compared to the other two-drug combinations. Surprisingly, in the UT-OV-3B cell line (serous cystadenocarcinoma) single-agent paclitaxel was more effective than the combination of paclitaxel and carboplatin and almost as effective as the combination of the three drugs ( $44 \%$ vs. $46 \%)$. These data are, however, in line with our previous study examining endometrial cancer cell lines (29). Adding carboplatin did not provide any additive or synergistic effect. This is strange because serous cystadenocarcinoma is generally sensitive for carboplatin. UT-OV-3B cell line was stage III or IV but it might have been low-grade serous carcinoma which is more often platinum resistant. It is also possible that the concentrations we used were suboptimal. Fanning et al. (37) compared cytotoxicity concentrations of cisplatin and carboplatin and in their study the $\mathrm{IC}_{50}$ value for carboplatin was as high as $490 \mu \mathrm{g} / \mathrm{ml}$ with exposure periods $1,4,24$ and $48 \mathrm{~h}$. They used the commercial OVCAR-3 cell line. For a specific patient after the dose of $350 \mathrm{mg} / \mathrm{m}^{2}$ carboplatin, the peak
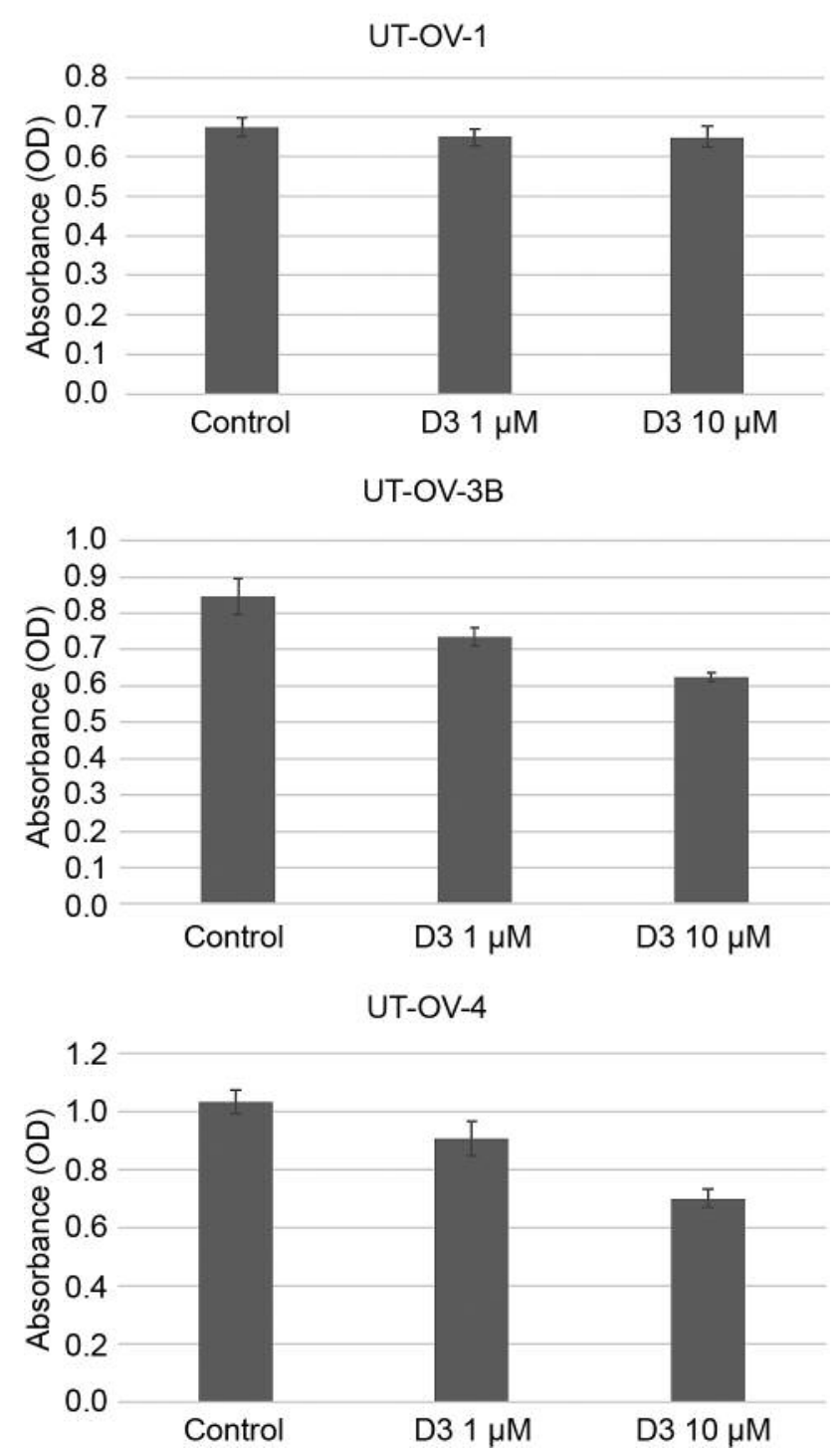

Figure 2. Effect of cytotoxic agents on UT-OV-1, UT-OV-3B and UT$O V-4$ ovarian cancer cell growth. The cells were treated for three days with indicated drugs and optical density (OD) was measured at $590 \mathrm{nM}$. $O D$ is directly proportional to cell biomass. Mean and SD of six replicates are shown. P: Paclitaxel, Ca: carboplatin.

plasma level was $123 \mu \mathrm{M}(45 \mu \mathrm{g} / \mathrm{ml})$ (38) which is almost the same concentration we used in the UT-OV-3B cell line. As this is a small in vitro study our results need to be confirmed by aid of in vivo epithelial ovarian cancer (EOC) models. However, we used non-commercial well-established cell lines, which should closer resemble the original tumors than the commercial ones, and at least additive anti-tumor effect was seen in all but one of the cell lines.

The UT-OV-1 cell line was mucinous cystadenocarcinoma and UT-OV-4 endometrioid cystadenocarcinoma. Both cell lines have been earlier shown to be sensitive to paclitaxel, 


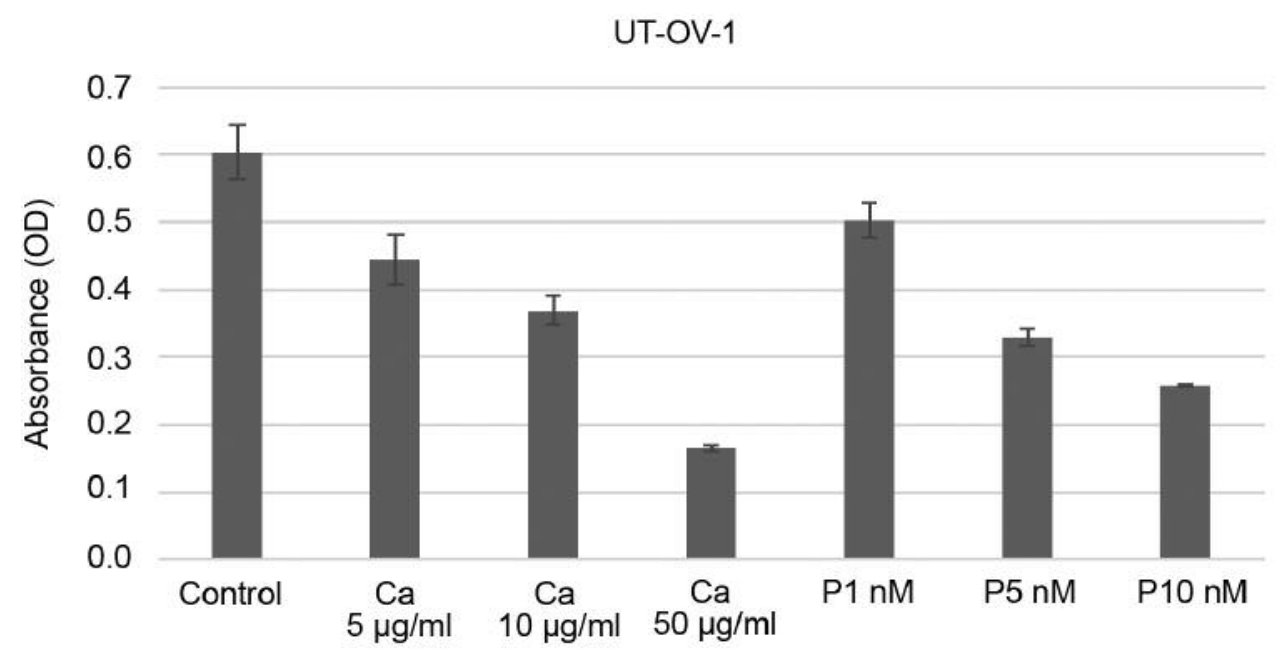

UT-OV-3B
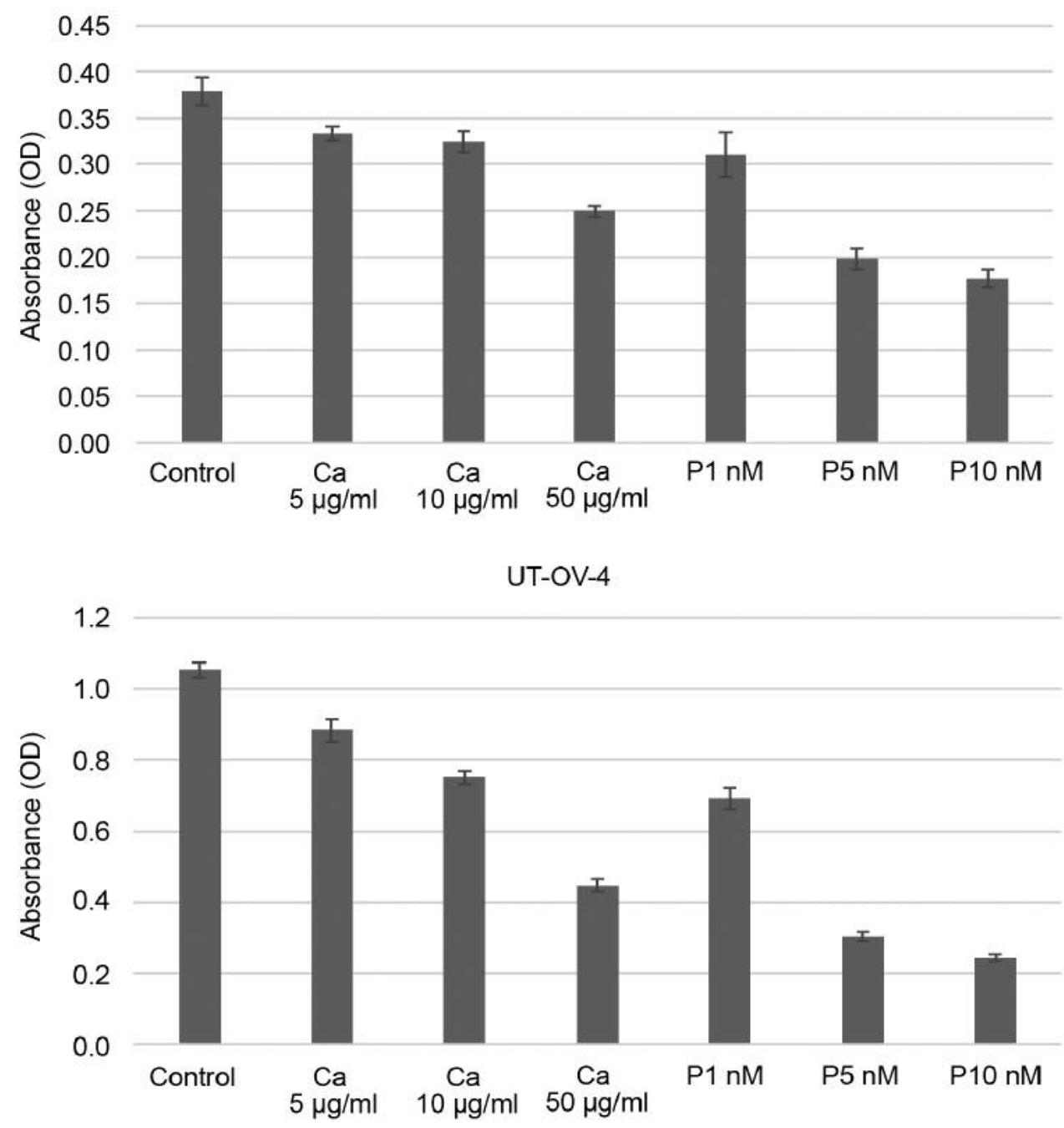

Figure 3. Effect of various concentrations of 1,25-D3 on UT-OV-1, UT-OV-3B and UT-OV-4 ovarian cancer cell growth. The cells were treated for three days with indicated concentrations of 1,25-D3 and optical density $(O D)$ was measured at $590 \mathrm{nM}$. OD is directly proportional to the cell biomass. Mean and SD of six replicates is shown. D3: 1,25-D3. 
Table I. The percentage of cytotoxicity of single agents and of different combination of drugs in three different ovarian carcinoma cell lines (UT-OV-1, UT-OV-3B, UT-OV-4). P: Paclitaxel; Ca: carboplatin; D3: 1,25-D3

\begin{tabular}{lccc}
\hline Cytotoxicity & UT-OV-4 & UT-OV-3B & UT-OV-1 \\
\hline D3 $\quad 10 \mu \mathrm{M}$ & $28 \%$ & $23 \%$ & $3 \%$ \\
P $\quad 1 / 5 / 5 \mathrm{nM}$ & $36 \%$ & $44 \%$ & $48 \%$ \\
$\mathrm{Ca} \quad 10 / 50 / 10 \mu \mathrm{g} / \mathrm{ml}$ & $30 \%$ & $29 \%$ & $29 \%$ \\
$\mathrm{P}+\mathrm{Ca}$ & & $47 \%$ & $33 \%$ \\
$56 \%$ & & & \\
P + D3 & $46 \%$ & $39 \%$ & $50 \%$ \\
$\mathrm{Ca}+\mathrm{D} 3$ & $47 \%$ & $35 \%$ & $36 \%$ \\
$\mathrm{P}+\mathrm{Ca}+\mathrm{D} 3$ & $58 \%$ & $46 \%$ & $61 \%$ \\
\hline
\end{tabular}

carboplatin and cisplatin (31). Although this finding is in line with our results, the sensitivity of the UT-OV-1 is quite surprising, as mucinous ovarian cancer is generally considered resistant to platinum-based chemotherapy (3940). Moreover, mucinous ovarian cancer cell lines have been found to have intrinsic platinum resistance (41). Because of our contrasting result, we confirmed the mucinous character of the UT-OV-1 by immunohistochemistry. The tumor cells were positive for CDX2, CEA, CK7 and p53, which are features of ovarian mucinous adenocarcinoma, intestinal type $(42,43)$. This discrepancy might be due to the availability of better diagnostic tools which has led to improved histopathological diagnosis of different types of mucinous ovarian cancer. Mucinous ovarian cancer has also several common pathological and molecular features with gastrointestinal tumors and it has been recently reviewed that altered mucin expression indicates chemoresistance in breast and colon cancer (44), but no data regarding the effect of altered mucin expression has to our knowledge been reported in ovarian cancer.

However, there is both experimental and clinical evidence that the platinum resistance of mucinous ovarian cancer is not universal. Ricci et al. (45) reported the molecular, metabolic and pharmacological characterization of two patient derived xenografts (PDXs) \#164 and \#182 from mucinous ovarian carcinomas. PDX\#164 was derived from a Stage IV tumor and PDX\#182 from a Stage I tumor. PDX\#164 was found to be moderately sensitive to both platinum and paclitaxel while PDX\#182 was not.

In retrospective clinical series response rates have varied between 13-60\% to first-line carboplatin and paclitaxel chemotherapy among women with mucinous ovarian cancer (46). The biological actions of 1,25-D3 are mediated by VDR, mostly via genomic pathways. The expression of VDR by cancer cells is required for the anti-proliferative effects of 1,25-D3 in vitro (10). However, there is evidence that
VDR expression or function may become aberrant during cancer development because of altered target gene regulation, overexpression of 1,25-D3 24-hydroxylase (catabolizing enzyme of 1,25-D3) or deregulation of pathways downstream of VDR (such as apoptosis) (25). Peng et al. (47) also reported that the antiproliferative effects of 1,25-D3 and its analogs and intact VDR-signaling machinery are dependent on a positive estrogen receptor status in breast cancer cell lines. On the other hand, it seems that in ovarian cancer there is no correlation with positive estrogen receptor status and 1,25-D3 actions (19). In our study three of five ovarian carcinoma cell lines were VDRpositive. Of note is that UT-OV-3B and UT-OV-4 strongly expressed VDR, while UT-OV-1, UT-OV-2 and UT-OV-3A did not. The explanation for the different actions of 1,25-D3 might be that VDR activity was disabled as described earlier.

Earlier studies support the present findings and the role of 1,25-D3 in cancer therapy. 1,25-D3 induces GADD45-gene and causes cell-cycle arrest at the G2/M transition in ovarian cancer cells (48). Furthermore, in a variety of studies a synthetic vitamin D analog (EB1809) has shown antiproliferative efficacy in ovarian tumors and tumor cells through induction of cell death, cell-cycle arrest, differentiation and inhibition of angiogenesis $(15,17,22$, 49). Lungchukiet et al. (50) demonstrated that 1,25-D3 suppresses epithelial ovarian cancer invasion into omentum in vitro and in an animal model through VDR-expression. In addition, 1,25-D3 has been found to be a potent inhibitor of ovarian cancer cell growth in vitro and increase the antiproliferative ability of carboplatin by altering the cell cycle and enhancing apoptosis (33). Liu et al. (51) found that 1,25-D3 delays the progression of ovarian cancer by increasing the expression of VDR and E-cadherin and decreasing $\beta$-catenin in vitro and in vivo in mouse models. This is in concordance with our results and provides evidence on the use of $1,25-\mathrm{D} 3$ as a potential therapeutic agent for ovarian cancer.

The authors are not aware of any studies comparing preclinically the effect of single-agents and the combination of 1,25-D3 and paclitaxel and carboplatin in ovarian cancer. The cytotoxic ability of single agents of 1,25-D3, paclitaxel and carboplatin has been evaluated in a wide panel of tumor types in vitro and in vivo, also in ovarian carcinoma (30-32, 34, 49, 52). Rodriquez et al. (53) examined the progestin/vitamin D combination in ovarian cancer cells and whether progestins inhibit the CYP24A1 enzyme. They demonstrated that theire combination synergistically reduced cell viability and induced apoptosis. Moreover, progestins inhibited CYP24A1, thus extending 1,25-D3 activity. Ly et al. (54) showed similar synergistic result with liarozole (an inhibitor of retinoic acid and aromatase) and 1,25-D3 in the aggressive prostate cancer cell line DU145. They suggested that this might be due to inhibition of 24-hydroxylase 


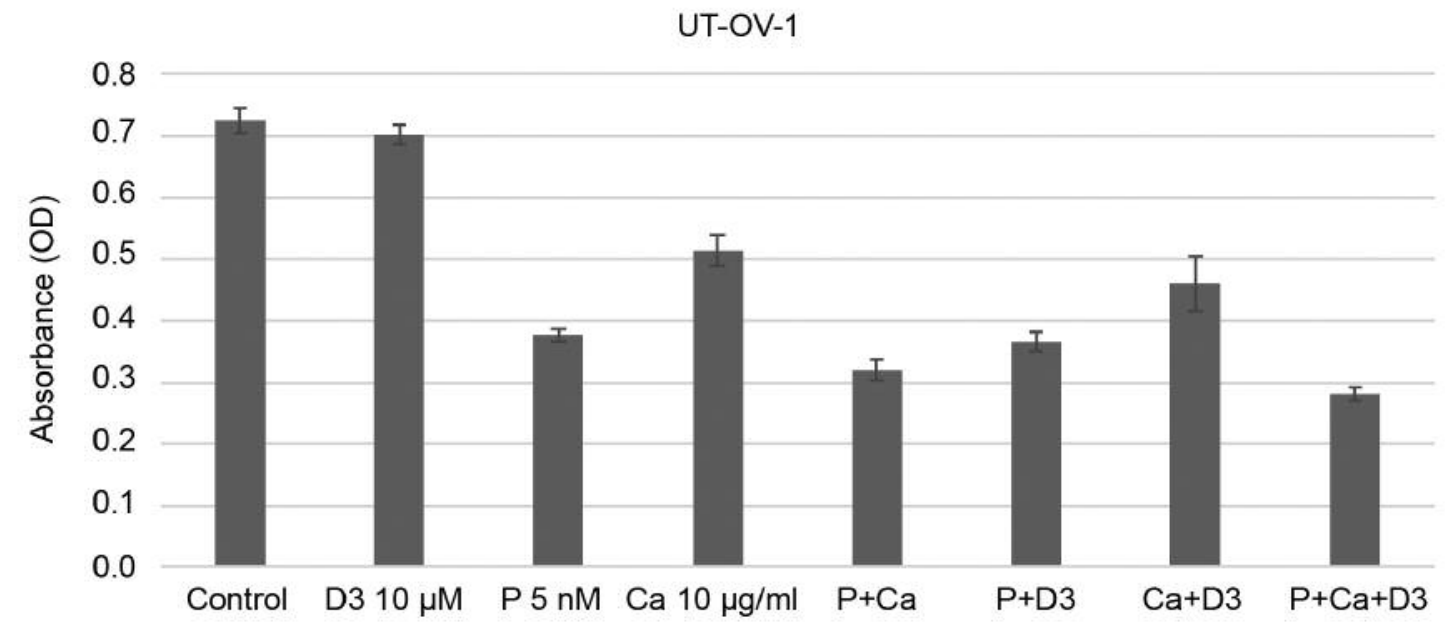

UT-OV-3B
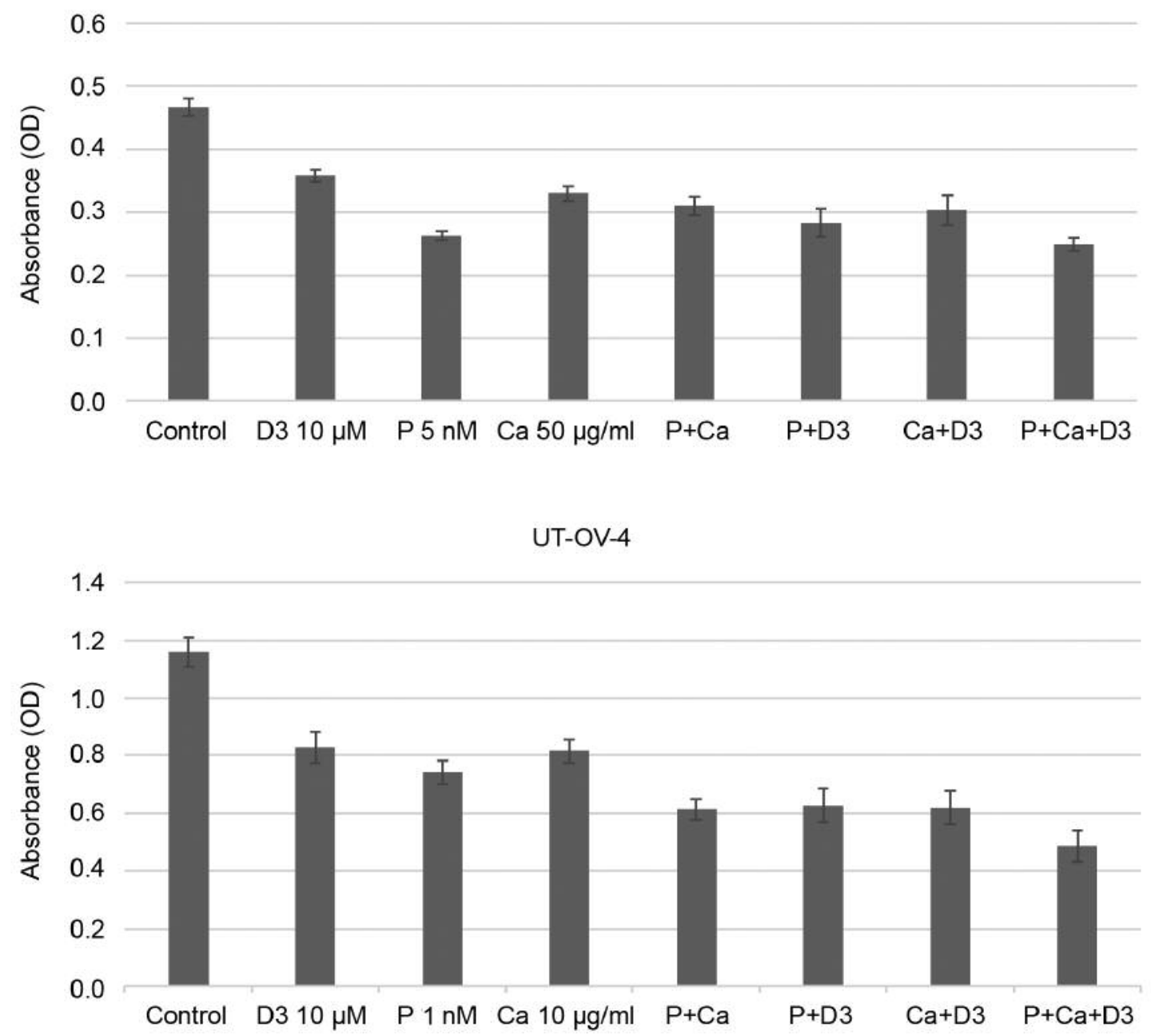

Figure 4. Cell growth inhibition in UT-OV-1, UT-OV-3B and UT-OV-4 ovarian cancer cells with different combinations of cytotoxic agents and 1,25-D3. The cells were treated for three days with indicated drugs and optical density (OD) was measured at 590 nM. OD is directly proportional to the cell biomass. Mean and SD of six replicates are shown. P: Paclitaxel, Ca: carboplatin, D3: 1,25-D3. 
activity, leading to increased 1,25-D3 half-life and VDR upregulation. Previous data suggest that the addition of 1,25 D3 to multiple chemotherapy regimens increases the activity of treatments and potentially leads to a better response rate to the regimens.

In conclusion, we demonstrated using three ovarian carcinoma cell lines that 1,25-D3 has growth inhibitory effect on VDR-expressing cell lines both alone and combined with paclitaxel and carboplatin. Further in vitro and in vivo studies are warranted for evaluation of the anticancer efficacy and the role of 1,25-D3 in relation to other ovarian cancer treatment modalities in the tumor microenvironment and in developed EOC models.

\section{Conflicts of Interest}

The Authors declare no conflicts of interest.

\section{Authors' Contributions}

Dr. Tea Kuittinen wrote the first draft of the manuscript, formed the figures and assisted the laboratory personnel at Prof. Kallioniemi's laboratory in the cell culture experiments. Dr. Päivi Rovio presented the original idea and reviewed the manuscript. Ms. Tiina Luukkaala performed the statistical analysis. Dr. Marita Laurila performed immunostainings. Prof. Seija Grenman provided the cell lines, established originally in her laboratory. Prof. Johanna Mäenpää, the senior author, and Prof. Anne Kallioniemi supervised the study, and revised the manuscript.

\section{References}

1 Bray F, Ferlay J, Soerjomataram I, Siegel RL, Torre LA and Jemal A: Global cancer statistics 2018: GLOBOCAN estimates of incidence and mortality worldwide for 36 cancers in 185 countries. CA Cancer J Clin 68(6): 394-424, 2018. PMID: 30207593. DOI: 10.3322/caac.21492

2 du BoisA, ReussA, Pujade-Lauraine E, Harter P, Ray-Coquard I, and Pfisterer J: Role of surgical outcome as prognostic factor in advanced epithelial ovarian cancer: a combined exploratory analysis of 3 prospectively randomized phase 3 multicenter trials: by the Arbeitsgemeinschaft Gynaekologische Onkologie Studiengruppe Ovarialkarzinom (AGO-OVAR) and the Groupe d'Investigateurs Nationaux pour les Etudes des Cancers de l'Ovaire (GINECO). Cancer 115(6): 1234-1244, 2009. PMID: 19189349. DOI: $10.1002 /$ cncr.24149

3 Timmermans M, Sonke GS, Van de Vijver KK, van der Aa MA and Kruitwagen RFPM: No improvement in long-term survival for epithelial ovarian cancer patients: A population-based study between 1989 and 2014 in the Netherlands. Eur J Cancer 88: 3137, 2018. PMID: 29179135. DOI: 10.1016/j.ejca.2017.10.030

4 Wimberger P Wehling M, Lehmann N, Kimmig R, Schmalfeldt B, Burges A, Harter P, Pfisterer J and du Bois A: Influence of residual tumor on outcome in ovarian cancer patients with FIGO stage IV disease: an exploratory analysis of the AGO-OVAR (Arbeitsgemeinschaft Gynaekologische Onkologie Ovarian Cancer Study Group). Ann Surg Oncol 17(6): 1642-1648, 2010. PMID: 20165986. DOI: 10.1245/s10434-010-0964-9
5 Rutten M, Sonke G, Westermann A, van Driel W, Trum J, Kenter $\mathrm{G}$ and Buist $\mathrm{M}$ : Prognostic value of residual disease after interval debulking surgery for FIGO stage IIIC and IV epithelial ovarian cancer. Obstet Gynecol Int 2015: 464123, 2015. PMID: 26106418. DOI: $10.1155 / 2015 / 464123$

6 Ataseven B, Grimm C, Harter P, Heitz F, Traut A, Prader S and du Bois A: Prognostic impact of debulking surgery and residual tumor in patients with epithelial ovarian cancer FIGO stage IV. Gynecol Oncol 140(2): 215-220, 2016. PMID: 2669122. DOI: 10.1016/j.ygyno.2015.12.007

7 Bouillon R, Van Cromphaut S and Carmeliet G: Intestinal calcium absorption: Molecular vitamin D mediated mechanisms. J Cell Biochem 88(2): 332-339, 2003. PMID: 12520535. DOI: $10.1002 /$ jcb. 10360

8 Fleet JC: Molecular regulation of calcium and bone metabolism through the vitamin D receptor: J Musculoskelet Neuronal Interact 6(4): 336-337, 2006. PMID: 17185813.

9 Fleet JC and Schoch RD: Molecular mechanisms for regulation of intestinal calcium absorbtion by vitamin $\mathrm{D}$ and other factors. Crit Rec Clin Lab Sci 47: 181-95, 2010. PMID: 21182397. DOI: 10.3109/10408363.2010.536429

10 Zinser GM, McEleney K and Welsh JE: Characterization of mammary tumor cell lines from wild type and vitamin D3 receptor knockout mice. Mol Cell Endocrinol 200(1-2): 67-80, 2003. PMID: 12644300. DOI: 10.1016/S0303-7207(02)00416-1

11 Zinser GM and Welsh JE: Vitamin D receptor status alters mammary gland morphology and tumorigenesis in MMTV-neu mice. Carcinogenesis 25(12): 2361-2372, 2004. PMID: 15333467. DOI: $10.1093 /$ carcin/bgh 271

12 Wu G, Fan RS, Li W, Ko TC and Brattain MG: Modulation of cell cycle control by vitamin D3 and its analogue EB 1089, in human breast cancer cells. Oncogene 15(13): 1555-1563, 1997. PMID 9380407. DOI: 10.1038/sj.onc.1201329

13 Liu M, Lee MH, Cohen M, Bommakanti M and Freedman LP: Transcriptional activation of the Cdk inhibitor $\mathrm{p} 21$ by vitamin D3 leads to the induced differentiation of the myelomonocytic cell line U937. Genes Dev 10(2): 142-153, 1996. PMID: 8566748. DOI: $10.1101 / \operatorname{gad} .10 .2 .142$

14 Welsh J, Simboli-Campbell M, Narvaez CJ and Tenniswood M: Role of apoptosis in the growth inhibitory effects of vitamin D in MCF-cells. Adv Exp Med Biol 375: 45-52, 1995. PMID: 7645427. DOI: 10.1007/978-1-4899-0949-7_4

15 Mantell DJ, Owens PE, Bundred NJ, Mawer EB and Canfield AE: 1 alpha,25-dihydroxyvitamin D (3) inhibits angiogenesis in vitro and in vivo. Circ Res 87(3): 214-220, 2000. PMID: 10926872. DOI: 10.1161/01.RES.87.3.214

16 Trump DL, Herschberger PA, Bernardi RJ, Ahmed S, Muindl J, Fakih M, Yu WD and Johnson CS: Anti-tumor activity of calcitriol: preclinical and clinical studies. J Steroid Biochem Mol Biol 89-90(1-5): 519-526, 2004. PMID: 15225831. DOI: 10.1016/j.jsbmb.2004.03.068

17 Ylikomi T, Laaksi I, Lou YR, Martikainen P, Miettinen S, Pennanen P, Purmonen S, Syvälä H, Vienonen A and Tuohimaa P: Antiproliferative action of vitamin D. Vitam Horm 64: 357-406, 2002. PMID: 11898396. DOI: 10.1016/s0083-6729(02)64010-5

18 Ahonen MH, Zhuang YH, Aine R, Ylikomi T andTuohimaa P: Androgen receptor and vitamin $\mathrm{D}$ receptor in human ovarian cancer: growth stimulation and inhibition by ligands. Int J Cancer 86(1): 40-46, 2000. PMID: 10728592. DOI: 10.1002/(SICI)10970215(20000401)86:1\%3C40::AID-IJC6\%3E3.0.CO;2-E 
19 Villena-Heinsen C, Meyberg R, Axt-Fliedner R, Reitnauer K, Reichrath $\mathrm{J}$ and Friedrich M: Immunohistochemical analysis of 1,25-dihydroxyvitamin-D3-receptors, estrogen and progesterone receptors and $\mathrm{Ki}-67$ in ovarian carcinoma. Anticancer Res 22: 2261-2267, 2002. PMID: 12174912.

20 Friedrich M, Rafi L, Mitschele T, Tilgen W, Schmidt W and Reichrath J: Analysis of the vitamin D system in cervical carcinomas, breast cancer and ovarian cancer. Recent Results Cancer Res 164: 239-246, 2003. PMID: 12899526. DOI: 10.1007/978-3-642-55580-0_17

21 Anderson MG, Nakane M, Ruan X, Kroeger PE and Wu-Wong JR: Expression of VDR and CYP24A1 mRNA in human tumors. Cancer Chemother Pharmacol 57(2): 234-240, 2006. PMID: 16180015. DOI: $10.1007 / \mathrm{s} 00280-005-0059-7$

22 Thill M, Woeste A, Reichert K, Fischer D, Rody A, Friedrich M and Koster F: Vitamin D inhibits ovarian cancer cell line proliferation in combination with celecoxib and suppresses cyclo-oxygenase-2 expression. Anticancer Res 35(2): 1197-1203, 2015. PMID: 22213328. DOI: 35/2/1197.full

23 Gnagnarella P, Pasquali E, Serrano D, Raimondi S, Disalvatore D and Gandini S: Vitamin D receptor polymorphism FokI and cancer risk: a comprehensive meta-analysis. Carcinogenesis 35(9): 1913-1919, 2014. PMID: 25053622. DOI: $10.1093 /$ carcin/bgu150

24 Höbaus, J, Thiem, U, Hummel, MD and Kallay E: Role of calcium, vitamin $\mathrm{D}$, and the extrarenal vitamin $\mathrm{D}$ hydroxylases in carcinogenesis. Anticancer Agents 13(1): 20-35, 2013. PMID: 23094918. DOI: $10.2174 / 187152013804487434$

25 Welsh J: Cellular and molecular effects of vitamin D on carcinogenesis. Arch Biochem Biophys 523(1): 107-114, 2012. PMID: 22085499. DOI: 10.1016/j.abb.2011.10.019

26 Ong J-S, Cuellar-Partida G, Lu Y, Fasching PA, Hein A and Burghaus $S$ et al: Association of vitamin D levels and risk of ovarian cancer: a Mendelian randomization study. Int J Epidemiol 45(5): 1619-1630, 2016. PMID: 27594614. DOI: 10.1093/ije/dyw207

27 Webb PM, de Fazio A, Protani MM, Ibiebele TI, Nagle CM, Brand AH, Blomfield PI, Grant P, Perrin LC and Neale RE: Circulating 25-hydroxyvitamin D and survival in women with ovarian cancer. Am J Clin Nutr 102(1): 109-114, 2015. PMID: 25971716. DOI: 10.3945/ajcn.114.102681

28 Yin L, Grandi N, Raum E, Haug U, Arndt V and Brenner H: Meta-analysis: Circulating vitamin D and ovarian cancer risk. Gynecol Oncol 121: 369-375, 2011. PMID: 21324518. DOI: 10.1016/j.ygyno.2011.01.023

29 Kuittinen T, Rovio P, Staff S, Luukkaala T, Kallioniemi A, Grenman S, Laurila M and Maenpaa J: Paclitaxel, carboplatin and 1,25-D3 inhibit proliferation of endometrial cancer cells in vitro. Anticancer Res 37(12): 6575-6581, 2017. PMID: 29187432. DOI: 10.21873 /anticanres.12114

30 Engblom P, Rantanen V, Kulmala $J$ and Grenman S: Carboplatin-paclitaxel- and carboplatin docetaxel-induced cytotoxic effect in epithelial ovarian carcinoma in vitro. Cancer 86(10): 2066-2073, 1999. PMID: 10570433. DOI: 10.1002/(SICI)1097-0142(19991115)86:10\%3C2066::AIDCNCR26\%3E3.0.CO;2-1

31 Engblom P, Rantanen V, Kulmala J and Grenman S: Paclitaxel and cisplatin sensitivity of ovarian carcinoma cell lines tested with the 96-well plate clonogenic assay. Anticancer Res 16(4A): 1743-1748, 1996. PMID: 8712694.
32 Engblom P, Pulkkinen JO, Rantanen V, Hirvonen H, Kulmala J, Grenman R and Grenman S: Effects of paclitaxel with or without cremophor EL on cellular clonogenic survival and apoptosis. Eur J Cancer 35(2): 284-288, 1999. PMID: 10448272. DOI: 10.1016/S0959-8049(98)00298-6

33 Zhang Z, Zhang H, Hu Z, Wang P, Wan J and Li B: Synergy of 5-dihydroxyvitamin D3 and carboplatin in growth suppression of SKOV-3 cells. Oncol Lett 8(3): 1348-1354, 2014. PMID: 25120722. DOI: $10.3892 / \mathrm{ol} .2014 .2307$

34 Hou YF, Gao SH, Wang P, Zhang HM, Liu LZ, Ye MX, Zhuo GM, Zhang ZL and Li BY: $1 \alpha, 25(\mathrm{OH}) \mathrm{D} 2 \mathrm{D} 3$ suppresses the migration of ovarian cancer SKOV-3 cells through the inhibition of epithelial-mesenchymal transition. Int J Mol Sci 17: 12851291, 2016. PMID: 27548154. DOI: 10.3390/ijms 17081285

35 Grénman S, Engblom P, Rantanen V, Klemi P and Isola J: Cytogenetic Characterization of five new ovarian carcinoma cell lines. Acta Obstet Gynecol Scand 76: 83, 1997.

36 Bläuer M, Rovio PH, Ylikomi T and Heinonen PK: Vitamin D inhibits myometrial and leiomyoma proliferation in vitro. Fertil Steril 91(5): 1919-1925, 2009. PMID: 18423458. DOI: 10.1016/j.fertnstert.2008.02.136

37 Fanning J, Biddle WC, Goldrosen M, Crickard K, Crickard U, Piver MS and Foon KA: Comparison of cisplatin and carboplatin cytotoxicity in human ovarian cancer cell lines using the MTT assay. Gynecol Oncol 39(2): 119-122, 1990. PMID: 1699853. DOI: $10.1016 / 0090-8258(90) 90416-\mathrm{I}$

38 Elferink F, van der Vijgh WJ, Klein I, Vermoken JB, Gall HE and Pinedo HM: Pharmacokinetics of carboplatin after iv administration. Cancer Treat Rep 71(12): 1231-1237, 1987. PMID: 3319135.

39 Pectasides D, Fountzilas G, Aravantinos G, Kalofonos HP, Efstathiou E, Salamalekis E, Farmakis D, Skarlos D, Briasoulis E, Economopoulos T and Dimopoulos MA: Advanced stage mucinous epithelial ovarian cancer: The Hellenic Cooperative Oncology Group experience. Gynecol Oncol 97(2): 436-441, 2005. PMID: 15863142. DOI: 10.1016/j.ygyno.2004.12.056

40 Alexandre J, Ray-Coquard I, Selle F, Floquet A, Cottu P, Weber B, Falandry C, Lebrun D and Pujade-Lauraine E: GINECO Mucinous advanced epithelial ovarian carcinoma: Clinical presentation and sensitivity to platinum-paclitaxel-based chemotherapy, the GINECO experience. Ann Oncol 21(12): 23772381, 2010. PMID: 20494964. DOI: 10.1093/annonc/mdq257

41 Shimizu Y, Nagata H, Kikuchi Y, Umezawa S, Hasumi K and, Yokokura T: Cytotoxic agents active against mucinous adenocarcinoma of the ovary. Oncol Rep 5(1): 99-101, 1998. PMID: 9458301. DOI: 10.3892/or.5.1.99

42 Lin W, Cao D and Shen K: Prognostic significance of preoperative serum CEA in primary mucinous ovarian carcinoma: a retrospective cohort study. Cancer Manag Res 10: 6913-6920, 2018. PMID: 30588097. DOI: 10.2147/CMAR.S186258

43 Bassiouny D, Ismiil N, Dube V, Han G, Cesari M, Lu FI, Slodkowska E, Parra-Herran C, Chiu HF, Naeim M, Li N, Khalifa $\mathrm{M}$ and Nofech-Mozes S: Comprehensive clinicopathologic and updated immunohistochemical characterization of primary ovarian mucinous carcinoma. Int J Surg Pathol 26(4): 306-317, 2018. PMID: 29338553. DOI: 10.1177/1066896917752861

44 Jonckheere N, Skrypek N and Van Seuningen I: Mucins and tumor resistance to chemotherapeutic drugs. Biochim Biophys Acta 1846(1): 142-151, 2014. PMID: 24785432. DOI: 10.1016/ j.bbcan.2014.04.008 
45 Ricci F, Guffanti F, Affatato R, Brunelli L, Roberta P, Fruscio R, Perego P, Bani M, Chiorino G, RInaldi A, Bertoni F, Fratelli $M$ and Damia G: Establishment of patient-derived tumor xenograft models of mucinous ovarian cancer. Am J Cancer Res 10(2): 572-580, 2020. PMID: 32195028.

46 Morice P, Gouy S and Leary M: Mucinous ovarian carcinoma. New Engl J Med 380: 1256-1266, 2019. PMID: 30917260. DOI:10.1056/NEJMra1813254

47 Peng X, Jhaveri P, Hussain-Hakimjee EA and Mehta RG: Overexpression of ER and VDR is not sufficient to make ERnegative MDA-MB231 breast cancer cells responsive to 1alphahydroxyvitamin D5. Carcinogenesis 28(5): 1000-1007, 2007. PMID: 17130524. DOI: $10.1093 /$ carcin/bgl230

48 Jiang F, Pengfrei Li, Fornace AJ Jr, Nicosia SV and Wenlong B: G2/M arrest by 1,25-dihydroxyvitamin D3 in ovarian cancer cells mediated through the induction of GADD45 via an exonic enhancer. J Biol Chem 278(48): 48030-48040, 2003. PMID: 14506229. DOI: $10.1074 /$ jbc.M308430200

49 Deuster E, Jeschke U, Ye Y, Mahner S and Czogalla B: Vitamin $\mathrm{D}$ and VDR in gynecological cancers - A systematic review. Int J Mol Sci 18(11): 2328, 2017. PMID: 29113037. DOI: $10.3390 / \mathrm{ijms} 18112328$

50 Lungchukiet P, Sun Y, Kasiappan R, Quarni W, Nicosia SV, Zhang $\mathrm{X}$ and Bai W: Suppression of epithelial ovarian cancer invasion into the omentum by $1 \alpha, 25$-dihydroxyvitamin $\mathrm{D} 3$ and its receptor. J Steroid Biochem Mol Biol 148: 138-147, 2015. PMID: 25448740. DOI: 10.1016/j.jsbmb.2014.11.005
51 Liu L, Hu Z, Zhang H, Hoy Y, Zhang Z, Zhou G and Li B: Vitamin $D$ postpones the progression of epithelial ovarian cancer induced by 7, 12-dimethylbenz [a] anthracene both in vitro and in vivo. Onco Targets Ther 19(9): 2365-2375, 2016. PMID: 27143932. DOI: $10.2147 /$ OTT.S100581

52 Leyssens C, Verlinden L and Verstuyf, A: Antineoplastic effects of $1,25(\mathrm{OH}) 2 \mathrm{D} 3$ and its analogs in breast, prostate and colorectal cancer. Endocr Relat Cancer 20(2): 31-47, 2013. PMID: 23319494. DOI: $10.1530 /$ ERC-12-0381

53 Rodriguez GC, Turbov J, Rosales R, Yoo J, Hunn J, Zappia KJ, Lund K, Barry CP, Rodriquez IV, Pike JW, Conrads TP, Darcy KM, Maxwell GL, Hamilton CA, Syed V and Thaete LG: Progestins inhibit calcitriol induced CYP24A1 and synergistically inhibit ovarian cancer cell viability: An opportunity for chemoprevention. Gynecol Oncol 143(1): 159-167, 2016. PMID: 27106018. DOI: 10.1016/j.ygyno.2016.04.022

54 Ly LH, Zhao XY, Holloway L and Feldman D: Liarozole acts synergistically with 1 $\alpha, 25$-dihydroxyvitamin D3 to inhibit growth of DU 145 prostate cancer cells by blocking 24hydroxylase activity. Endocrinology 140(5): 2071-2076, 1999. PMID: 10218956. DOI: 10.1210/endo.140.5.6698

Received March 31, 2020

Revised April 21, 2020

Accepted April 24, 2020 